\title{
Comparative Study of One-Bid versus Two-Bid Auctions*
}

\author{
Radosveta Ivanova-Stenzel ${ }^{\dagger}$ and Doron Sonsino ${ }^{\ddagger}$ \\ Humboldt University Berlin, Technion Haifa
}

September 19, 2001

\begin{abstract}
We compare the standard one-bid first price auction to a corresponding two-bid first price auction where each buyer may place two bids: a high bid and a low one and the winner pays his low bid if this was higher than all other bids. We characterize the equilibria of the two mechanisms and prove some results on the ranking of revenues and expected utilities across the two mechanisms for the symmetric case. We show that subjects in a computerized experiment prefer the two-bid auction over the one-bid auction when given the possibility of choosing among the two and we claim that this and other aspects of subjects' behavior conform to the equilibrium predictions for risk-averse subjects. We also report some discrepancies between the experimental results and the equilibrium predictions and provide some alternative explanations to the observed behavior.
\end{abstract}

JEL classification: D44, C91

Keywords: sealed-bid private-value auctions, experiments

*We thank Jörg Breitung, Werner Güth, Sabine Kröger, Dan Levin, Dov Monderer, Timothy Salmon, Amnon Rapoport, Frank Riedel, participants of a seminar at the Hebrew University as well as at the ESA meeting 2001 for helpful comments. Financial support from the Israeli Ministry of Science and the fund for the promotion of research at the Technion is gratefully acknowledged.

${ }^{\dagger}$ Corresponding author: Department of Economics, Institute for Economic Theory III, Spandauer Strasse 1, 10178 Berlin, Germany, tel:+49/30/20935733, fax:+49/30/20935704, e-mail: ivanova@wiwi.huberlin.de

${ }^{\ddagger}$ Faculty of Industrial Engineering and Management, Technion 32000, Haifa, tel.:+ 972-4-829-4435, fax:+972-4-823-5194, e-mail: sonsino@ie.technion.ac.il 


\section{Introduction}

The dramatic increase in auction-trade volume over the last few years has been followed by an impressive increase in the variety of auction mechanisms used by the sellers. Leading listing auction-sites (Lucking-Reiley, 1999) on the Web like Ebay, Yahoo, City Auction, etc. offer the possibility to sell/buy products through (different variations on) standard English and Dutch auctions. Other auction sites employ a large variety of different auction mechanisms like sealed-bid auctions, auctions where player pay fixed participation fees and more. Indeed, it has been suggested (Monderer and Tennenholtz, 1998) that online auctioneers compete for the pool of potential buyers by choosing the auction type that would maximize their expected payoffs, while taking into account that buyers would choose the auction-site that maximizes their expected utilities.

This paper deals with a new type of auction that has recently appeared on the Web, a first-price auction where buyers may submit several bids for the same object. One of the largest auctions in Israel, "The State Auction," for example, allows each bidder to submit up to three different price proposals in each auction. ${ }^{1}$ The rules state that "if more than one of your offers has won, then the highest winning offers would be canceled and you would only pay your lower winning offer". The same is true for "The Double Auction", another leading auction in Israel. ${ }^{2}$ Here, you may submit up to 5 offers for the same product but you pay a per-offer participation fee so that as the number of offers you submit increases, you pay more.

With these examples as a motivation, this paper compares the standard (iid-assumption ${ }^{3}$, one indivisible object) first-price auction where each player may submit only one bid

\footnotetext{
1" The State Auction" is both, Web-based at http://www.e-hamichraz.co.il/ and published in a booklet, that is distributed with leading newspapers. Bidders may thus place bids through the Web or by calling a phone number.

${ }^{2}$ Again the auction is Web based at http://www.2bid.co.il but the catalogue also appears as a printed booklet.

${ }^{3}$ Subjects' private valuations are independent and identical (iid) draws from a uniform distribution $[a, b]$, where $a$ and $b$ are common knowledge.
} 
(henceforth: the one-bid auction) to a corresponding two-bid first-price auction (henceforth: the two-bid auction) where each player may submit two bids and the winner pays his low bid if this is higher than the highest bid submitted by his opponents. We characterize the (constant relative risk averse) equilibria of the two mechanisms and prove some results on the ranking of revenues and expected utilities across the two mechanisms for the symmetric case. Furthermore, we conduct an experiment where subjects play repeatedly one-bid auctions and two-bid auctions with randomly chosen partners and compare the experimental results with the equilibrium predictions.

One of the interesting features of our experiment is that, in the last phase of the experiment, subjects are repeatedly asked to choose between the two auction mechanisms. In particular, in the second phase of our experiment (after playing each auction type for 24 rounds in the first phase) subjects could choose (for 16 rounds) their favorite auction mechanism before observing their realized value. This enabled us to directly examine subjects' preferences across the two mechanisms and check the consistency of subjects' behavior with respect to the equilibrium benchmark.

Another non-standard feature of the experiment is that we allow subjects to submit bids that are lower than the minimum possible private value. Indeed, we find that many subjects bid less than the minimum value when given the opportunity.

The experimental literature on auction mechanisms in general and first-price privatevalue auctions in particular is too large to survey in this short introduction. ${ }^{4}$ Therefore, we will just mention some of the contributions. Cox et al.(1982, 1985, 1988, 1992) ran a comprehensive set of experiments trying to explain and characterize subjects' behavior in different auctions. Among the factors that they investigated are, e.g., the impact of the chosen price rule (see also Coppinger et al., 1980, Güth et al., 1999), the number of bidders (see also Kagel and Levin, 1993), subjects' motivation (see also Kagel and Levin, 1985, Kagel and Roth, 1992), the selected incentive scheme (see also Harrison,

\footnotetext{
${ }^{4}$ For more details and references see the survey by Kagel (1995).
} 
1989). In an effort to explain significant heterogeneity in individual bidding patterns, Cox et al. develop formal models where subjects have the constant relative coefficient of risk aversion (CRRA) type of utility functions (henceforth referred to as CRRAM). Chen and Plott (1998) investigate bidding behavior in auctions where the private valuations are drawn from nonuniform distributions. Pezanis-Christou (1998) and Güth et al.(2001) study different types of auctions with asymmetric bidders. However, all these studies focus on the traditional one-bid type of auctions. This paper is (to the best of our knowledge) the first study of multi-bid auctions where bidders may submit several bids for a given object.

Our main results can be summarized as follows:

(1) Subjects behave as if they are risk-averse in the sense of bidding more than the risk neutral equilibrium strategies in approximately $60 \%$ to $70 \%$ of the cases. Still, we find a robust inclination to "bargain-bid"; i.e., to bid prices that are below the lowest possible private value.

(2) The average prices collected by the seller and the average revenues to the buyers are not significantly different across the two mechanisms in the first phase of the experiment. Still, subjects reveal a robust inclination to prefer the two-bid mechanism over the one-bid mechanism in the second phase of the experiment.

The remainder of the paper is organized as follows: The theoretical results are presented in Section 2. The experimental procedure is described in Section 3 and the experimental results in Section 4. Section 5 concludes.

\section{A model}

Consider an independent private-value two-bidder auction where $V_{i} \sim U[0,1]$ for each bidder $i=1,2$. Let $v_{i} \in[0,1]$ denote the realized value of bidder $i$. We compare the case 
of a one-bid auction where each bidder $i$ may only submit one bid $b_{i}\left(v_{i}\right)$ to the case of a two-bid auction where each bidder $i$ may submit two bids: A high-bid $h_{i}\left(v_{i}\right)$ and a low-bid $l_{i}\left(v_{i}\right)$ where $l_{i}\left(v_{i}\right) \leq h_{i}\left(v_{i}\right)$ for every $v_{i} \in[0,1]$.

The rules of the one-bid auction are the standard rules for first-price sealed-bid auctions; i.e., the highest bidder wins the auction and pays his bid. The rules of the two-bid auction are as follows:

The bidder who has submitted the highest bid wins the auction. If both bidders have submitted the same highest offer, the winner is randomly selected (with probability 0.5 for each bidder). If the winner's low-bid was strictly higher than the high-bid of the other bidder, then the winner pays his low-bid. Otherwise, the winner pays his high-bid.

As a benchmark for analyzing the experimental results that follow, we would like to characterize and compare the equilibria of the one-bid auction and the two-bid auction. First, we restrict the analysis to the case of bidders with symmetric preferences and assume that the utility function of the representative bidder takes the constant relative coefficient of risk aversion form $U(x)=x^{\alpha}$ for some $\alpha>0$ (see however Proposition 5 for the asymmetric case). Note that $\alpha<1$ describes a case where the agents are risk-averse, $\alpha=1$ is the case for risk-neutral agents, and $\alpha>1$ is the case for risk-seeking agents. Proposition 1 gives the symmetric equilibrium bidding strategies of the two games:

Proposition 1: The bidding strategy

$$
b^{*}(v)=\frac{1}{1+\alpha} \cdot v
$$

is a symmetric equilibrium of the one-bid auction. ${ }^{5}$

The bidding strategies

$$
l^{*}(v)=L(\alpha) \cdot v \quad \text { and } \quad h^{*}(v)=H(\alpha) \cdot v
$$

with

$$
L(\alpha)=\frac{1-\left[\frac{\alpha}{1+\alpha}\right]^{\alpha}}{1+\alpha-\left[\frac{\alpha}{1+\alpha}\right]^{\alpha}} \quad \text { and } \quad H(\alpha)=\frac{1+\alpha \cdot L(\alpha)}{1+\alpha},
$$

constitute a symmetric equilibrium of the two-bid auction.

\footnotetext{
${ }^{5}$ For notational convenience let $v$ rather than $v_{i}$ denote the realized value of bidder $i$.
} 
The derivation of the equilibrium strategies can be found in Appendix A.

Proposition 2: In equilibrium,

$$
b^{*}(v)=\frac{1}{2} v, \quad l^{*}(v)=\frac{1}{3} v \quad \text { and } \quad h^{*}(v)=\frac{2}{3} v
$$

when the bidders are risk-neutral;

$$
b^{*}(v)>\frac{1}{2} v, \quad l^{*}(v)>\frac{1}{3} v \quad \text { and } \quad h^{*}(v)>\frac{2}{3} v
$$

when the bidders are risk-averse;

$$
b^{*}(v)<\frac{1}{2} v, \quad l^{*}(v)<\frac{1}{3} v \quad \text { and } \quad h^{*}(v)<\frac{2}{3} v
$$

when the bidders are risk-seeking.

From Proposition 2 it immediately follows that the expected revenue for the seller is equal across the two auction-types when $\alpha=1 .{ }^{6}$ Proposition 3 compares the expected revenues for the seller from both auction types for other risk-preferences:

Proposition 3: In equilibrium, the expected revenue for the seller from the one-bid auction is higher than the expected revenue from the two-bid auction when the agents are risk-averse; the expected revenue for the seller from the two-bid auction is higher than the expected revenue from the one-bid auction when the bidders are risk-seeking.

The next proposition compares the expected utility of the bidder across the two mechanisms for different $\alpha$-types.

Proposition 4: In equilibrium, for every $v \in[0,1]$, the expected utility of the bidder with valuation $v$ from the two-bid auction is higher than his expected utility from the one-bid auction when the bidder is risk-averse; the expected utility from the one-bid auction is higher than the expected utility from the two-bid auction when the bidder is risk-seeking; the expected utilities are equal across the two mechanisms when the bidder is risk-neutral.

\footnotetext{
${ }^{6}$ By standard arguments, this also follows from the Revenue-Equivalence Theorem.
} 
Our final proposition generalizes Proposition 1 and the inequalities of Proposition 2 by claiming that the corresponding results apply to the asymmetric CRRAM (see Cox et al., 1982) where the utility function of agent $i$ takes the form $U_{i}\left(x_{i}\right)=x_{i}^{\alpha_{i}}$ and $\alpha_{1} \neq \alpha_{2}{ }^{7}$

Proposition 5: Assume (w.l.g.) that $\alpha_{1} \geq \alpha_{2}$. The bidding strategy

$$
b_{i}^{*}\left(v_{i}\right)=\frac{1}{1+\alpha_{i}} \cdot v_{i}
$$

for $v_{i} \leq \frac{1+\alpha_{2}}{1+\alpha_{1}}$, characterizes an equilibrium of the one-bid auction.

The bidding strategies

$$
l_{i}^{*}\left(v_{i}\right)=L\left(\alpha_{i}\right) \cdot v_{i} \quad \text { and } \quad h_{i}^{*}\left(v_{i}\right)=H\left(\alpha_{i}\right) \cdot v_{i}
$$

with

$$
L\left(\alpha_{i}\right)=\frac{1-\left[\frac{\alpha_{i}}{1+\alpha_{i}}\right]^{\alpha_{i}}}{1+\alpha_{i}-\left[\frac{\alpha_{i}}{1+\alpha_{i}}\right]^{\alpha_{i}}} \quad \text { and } \quad H\left(\alpha_{i}\right)=\frac{1+\alpha_{i} \cdot L\left(\alpha_{i}\right)}{1+\alpha_{i}},
$$

for $v_{i} \leq \frac{H\left(\alpha_{1}\right)}{H\left(\alpha_{2}\right)}$, characterize an equilibrium of the two-bid auction.

In equilibrium

$$
b_{i}^{*}\left(v_{i}\right)=\frac{1}{2} v_{i}, \quad l^{*}\left(v_{i}\right)=\frac{1}{3} v_{i} \quad \text { and } \quad h\left(v_{i}\right)=\frac{2}{3} v_{i}
$$

when bidder $i$ is risk-neutral;

$$
b_{i}^{*}\left(v_{i}\right)>\frac{1}{2} v_{i}, \quad l^{*}\left(v_{i}\right)>\frac{1}{3} v_{i} \quad \text { and } \quad h\left(v_{i}\right)>\frac{2}{3} v_{i}
$$

when bidder $i$ is risk-averse;

$$
b_{i}^{*}\left(v_{i}\right)<\frac{1}{2} v_{i}, \quad l^{*}\left(v_{i}\right)<\frac{1}{3} v_{i} \quad \text { and } \quad h\left(v_{i}\right)<\frac{2}{3} v_{i}
$$

when bidder $i$ is risk-seeking.

\footnotetext{
${ }^{7}$ Note, however, that Propositions 3 and 4 cannot be directly generalized to the case of asymmetric bidders. In particular, note that in the asymmetric case, one bidder might be risk-averse while the other is risk-seeking so that the revenue for the seller and the expected utility of the buyer depend more complicatedly on the risk-preferences of both participants.
} 
The proof (with all other proofs) can be found in Appendix A.

Finally note that by standard arguments the corresponding equilibrium strategies for the case where subjects' valuations are drawn from the interval $[a, b]$ are

$$
\begin{gathered}
b^{*}(v)=a+\frac{1}{1+\alpha} \cdot(v-a) \\
l^{*}(v)=a+L(\alpha) \cdot(v-a) \text { and } h^{*}(v)=a+H(\alpha) \cdot(v-a)
\end{gathered}
$$

with $L(\alpha)$ and $H(\alpha)$ as defined in equations (3.3) above.

Observe also that since

$$
L(\alpha) \leq \frac{1}{1+\alpha} \leq H(\alpha)
$$

independent of $\alpha$,

$$
l(v) \leq b(v) \leq h(v)
$$

for every $v$ independent of the risk preferences of the agents.

In the proceeding analysis we use these equilibria and the propositions above as a benchmarks for analyzing the experimental results. ${ }^{8}$

\section{$3 \quad$ Experimental design}

The experimental sessions were subdivided into two distinct phases. In the first phase the subjects played repeatedly the two different auction types (one-bid and two-bid auctions) for 48 consecutive rounds. First, they played 6 rounds of the one-bid auction; then 6 rounds of the two-bid auction. These twelve games formed the first block of the experiment. It was followed by three other similar blocks where each auction type was played for 6 consecutive rounds in the same order as in block 1. The number of participants in each session was 8 . In each round, the 8 subjects were randomly divided into four pairs. In the second phase of the experiment, the participants played repeatedly for 16 rounds an extended auction-selection game where bidders may choose their favorite auction type

\footnotetext{
${ }^{8}$ Note however that (because of the obvious technical constraints) in the experiment $v_{i}$ was drawn from the finite set $V=\{50,51,52, \ldots 148,149,150\}$.
} 
before observing their realized private value. To guarantee that an even number of subjects chooses each mechanism, we have only let 7 out of the 8 participants choose their favorite auction type (one-bid or two-bid auction) in each round. The 8-th participant was automatically assigned to one of the auction types accordingly. The identity of the "8-th" player was changed in each round, so that each subject played the balancing role twice among the 16 rounds. After selecting the auction type for each pair, the corresponding auction was played just as in the first phase of the experiment.

The private values of the bidders in each round were randomly drawn from the set $V=\{50,51,52, \ldots 148,149,150\}$ with all values $v_{i} \in V$ being equally likely. Subjects could choose integer bids between 0 and $200 .{ }^{9}$ Thus bidders were allowed to underbid the lowest possible private value $v_{i}=50$ as well as to overbid the highest possible private value $v_{i}=150$. All values were denoted in a fictitious currency termed ECU for Experimental Currency Unit. Actual payments were determined according to the rules of the corresponding auction (see the Instructions in Appendix C). At the end of each round, the bidders observed a feedback-window specifying whether they have won the current auction or not, the final buying price, the bids of both participants, their own profit in the current round, their total profits up to the current round and their average profit in each auction type.

All experimental sessions were computerized. ${ }^{10}$ Most participants were students of economics or business administration at Humboldt University, Berlin. In total, an experimental session lasted about two hours. The conversion rate of the ECU earned by each subject into cash was: $1 \mathrm{ECU}=0.03 \mathrm{DM}$. In addition, subjects were paid a fixed participation fee of 10 DM. Subjects' total earnings ranged between 18.00 DM to 44.41 DM with a mean of 32.44 DM. Altogether, we ran 6 sessions resulting in 1152 (576 one-bid, 576 two-bid) auctions in the first phase and 384 (101 one-bid, 283 two-bid) auctions in the second phase.

\footnotetext{
${ }^{9}$ When comparing the experimental results to the equilibrium benchmarks we sometimes normalize the realized private values and the bids submitted in the experiment by subtracting 50 and dividing the difference by 100 .

${ }^{10}$ The software for the computerized experiment was developed with the help of z-Tree (Fischbacher, 1998).
} 


\section{Results}

\subsection{Bidding behavior}

\subsubsection{Overbidding realized values}

Bidding above one's private valuation always defines a weakly dominated strategy. In our sample, only 10 of the 1354 bids submitted in the one-bid auction were above value. Moreover, 9 of these 10 bids were submitted in the first block and are presumably due to initial problems in understanding the game rules (see Figure B.1 in Appendix B).

Overbidding was much more frequent in the two-bid auctions. The overbidding rate for these auctions was $3.84 \%$ (66 bids out of the 1718 high-bids submitted in these auctions). The overbidding rate was $4.8 \%$ for the first phase of the experiment and $1.9 \%$ for the second phase of the experiment. ${ }^{11}$ In only 3 cases did bidders submit a low-bid higher than their valuation; all these cases occurred in the first block of the experiment. A possible explanation for the high overbidding ratios observed in the two-bid auctions is a bidder's illusion that by submitting a large high-bid, he increases his chances of winning without increasing the buying price; i.e., he increases the chances of submitting the highest bid but eventually pay his low offer. The data indeed shows that in $40 \%$ of all overbidding cases in the first phase of the experiment, the overbidders ended up with positive payoffs. $^{12}$

\subsubsection{Bargain-bidding}

Recall that the minimal possible valuation for the buyer in our auctions was 50. It immediately follows that in equilibrium bidders should never bid less than $50 .{ }^{13}$ The experimental data set, however, shows that $7.7 \%$ of the bids submitted in one-bid auctions; $16.9 \%$ of the low-bids submitted in two-bid auctions and $5.8 \%$ of the high-bids

\footnotetext{
${ }^{11}$ The differences in overbidding ratios across the four blocks in the first phase were not statistically significant.

${ }^{12}$ Kagel, Harstad and Levin (1987) conjecture that in a second-price sealed-bid auction subjects also succumb to the illusion that bidding above their values increases their chances of winning without increasing the buying price; i.e., the bid of the other bidder.

${ }^{13}$ Bids equal to 50 might be submitted in equilibrium when the realized valuation of the buyer is 50 .
} 
submitted in two-bid auctions were lower than 50 . We henceforth refer to these cases as "bargain-bidding". Table 3.1 gives the proportion of bargain-bidding, the average bid submitted by bargain-bidders and the corresponding average values of bargain-bidders for each type of bid.

\begin{tabular}{|c|c|c|c|c|c|c|c|}
\hline \multicolumn{2}{|c|}{} & \multicolumn{2}{c|}{ one-bid } & \multicolumn{2}{c|}{ two-bid_high } & \multicolumn{2}{c|}{ two-bid_low } \\
\cline { 3 - 8 } \multicolumn{2}{|c|}{} & phase 1 & phase 2 & phase 1 & phase 2 & phase 1 & phase 2 \\
\hline \hline prop. & bargain-bid & $7.7 \%$ & $7.4 \%$ & $6.2 \%$ & $4.9 \%$ & $16.9 \%$ & $16.8 \%$ \\
\hline \multirow{2}{*}{ mean } & bargain-bid & 33 & 38 & 30 & 35 & 31 & 35 \\
\cline { 2 - 8 } & value & 63 & 58 & 60 & 58 & 66 & 66 \\
\hline
\end{tabular}

Table 3.1: Proportion of bargain-bidding, average bargain-bid, corresponding average value

The relatively high rates of extremely low bidding seems like an interesting feature of our experimental data set. A possible explanation could be the bidders' attempts to win the auction at special bargain-prices. Indeed the specific auctions mentioned in the introduction (and many other auction sites on the Web) frequently close with prices that are significantly lower than the perceived fair-market price for similar items. The possibility of buying the merchandise in a special bargain price seems to be one of the factors that drive potential buyers to these auctions.

Note that underbidding may be rationalized by claiming that bargain-bidders expect other bidders to go for such bargain-prices as well. Our data, however, shows that only $0.7 \%$ of the first-phase one-bid auctions (and $1.4 \%$ of the first-phase two-bid auctions) closed at prices lower than 50. Still, $7.4 \%$ of the one-bids, $16.8 \%$ of the low-bids and $4.9 \%$ of the high-bids submitted in the second phase of the experiment were lower than 50 (see Table 3.1). The proportions of lower-than-50 bids in the second phase of the experiment were not significantly different ${ }^{14}$ than the corresponding rates for the first phase. The inclination to bid lower than 50 thus seems robust with respect to the unsuccessful experience it produced at the first phase of the experiment.

\footnotetext{
${ }^{14}$ For each session.
} 


\subsubsection{Bidding relatively to RNE benchmark}

The formal results in Section 2 imply the following equilibrium benchmarks for riskneutral agents (henceforth referred to as the RNE strategies):

$$
\begin{gathered}
b^{*}(v)=50+\frac{1}{2} \cdot(v-50) \\
l^{*}(v)=50+\frac{1}{3} \cdot(v-50) \text { and } h^{*}(v)=50+\frac{2}{3} \cdot(v-50) .
\end{gathered}
$$

We employed a Wilcoxon test to check the null hypothesis that the observed bids are not significantly different from the equilibrium-benchmarks for risk-neutral agents, i.e., $b(v)-b^{*}(v)=0, h(v)-h^{*}(v)=0$ and $l(v)-l^{*}(v)=0$, respectively. We ran the test for each subject and each type of bid separately. Following the benchmarks of Proposition 2, we say that the subject bids as if (s)he is risk-averse when the Wilcoxon statistic is positive. We similarly say that the subject bids as if (s)he is risk-seeking when the statistic is negative. Table 3.2 gives the number of subjects classified as risk-averse and risk-seeking for each type of bid. The numbers in brackets state the number of subjects

\begin{tabular}{|c|c|c|c|c|c|c|c|}
\hline \multirow[b]{2}{*}{ Session } & \multirow{2}{*}{$\begin{array}{c}\text { Total } \\
\text { Nr. of } \\
\text { Subjects }\end{array}$} & \multicolumn{2}{|c|}{ one-bid } & \multicolumn{2}{|c|}{ two-bid_high } & \multicolumn{2}{|c|}{ two-bid_low } \\
\hline & & $\begin{array}{c}\text { risk- } \\
\text { averse }\end{array}$ & $\begin{array}{c}\text { risk- } \\
\text { seeking }\end{array}$ & $\begin{array}{c}\text { risk- } \\
\text { averse }\end{array}$ & $\begin{array}{c}\text { risk- } \\
\text { seeking }\end{array}$ & $\begin{array}{c}\text { risk- } \\
\text { averse }\end{array}$ & $\begin{array}{c}\text { risk- } \\
\text { seeking }\end{array}$ \\
\hline 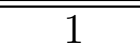 & $\overline{88}$ & $\begin{array}{ll}5(3) \\
\end{array}$ & "3(2) & $\overline{5} 5(4)$ & $\begin{array}{l}3(1) \\
\end{array}$ & $4 \overline{4(2)}$ & $4 \quad 4(1)$ \\
\hline 2 & 8 & $6(4)$ & $2(0)$ & $6(6)$ & $2(2)$ & $6(5)$ & $2(2)$ \\
\hline 3 & 8 & $6(4)$ & $2(1)$ & $5(4)$ & $3(1)$ & $6(4)$ & $2(2)$ \\
\hline 4 & 8 & $8(8)$ & $0(-)$ & $8(7)$ & $0(-)$ & $8(4)$ & $0(-)$ \\
\hline 5 & 8 & $6(6)$ & $2(2)$ & $7(5)$ & 1 (1) & $7(5)$ & $1(0)$ \\
\hline 6 & 8 & $7(4)$ & $1(1)$ & $5(4)$ & $3(2)$ & $5(4)$ & $3(2)$ \\
\hline 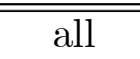 & $\overline{48}$ & $\begin{array}{lll}38 & (29)\end{array}$ & $\bar{~} 10(6)$ & $\begin{array}{l}36 \quad(30) \\
\end{array}$ & $\begin{array}{l}12(7) \\
\end{array}$ & 36 (24) & $\begin{array}{l}12(7) \\
\end{array}$ \\
\hline
\end{tabular}
for which the statistic is significant at $p \leq 0.05$ (two-tailed).

Table 3.2: Subjects classified by results of Wilcoxon test

Note that overall (across all sessions) the proportion of risk-averse behavior was not lower than $75 \%$ while the proportion of risk-seeking behavior was close to $25 \%$. These proportions seem reminiscent of those observed in Cox et al.(1988) and other experimental studies of first-price auctions and support the general belief that subjects act risk-averse rather than risk-seeking in first-price auctions (see Kagel, 1995). ${ }^{15}$

\footnotetext{
${ }^{15}$ These proportions are also close to those observed in many "other" past experiments on choice and
} 


\subsubsection{Bidding ratios}

Define the (revealed) bidding ratio of an agent with a realized valuation $v$ in a one-bid auction as follows 16

$$
r_{b}(v)=\frac{b(v)-50}{v-50}
$$

Similarly, define the (revealed) bidding ratios of the agent in a two-bid auction as

$$
r_{l}(v)=\frac{l(v)-50}{v-50} \quad \text { and } \quad r_{h}(v)=\frac{h(v)-50}{v-50}
$$

Recall (see the last paragraph of Section 2) that in equilibrium $r_{l}(v)<r_{b}(v)<r_{h}(v)$, for each value $v$, independent of the risk preferences of the subjects. In particular, for risk-neutral agents, $r_{l}(v)=1 / 3<r_{b}(v)=1 / 2<r_{h}(v)=2 / 3$. Indeed, when we average the three bidding ratios for each subject we find that $79.3 \%$ of the subjects conform with the prediction $r_{l}(v)<r_{b}(v)$, while $83.7 \%$ conform with the conjectured $r_{b}(v)<r_{h}(v) .{ }^{17}$

Table 3.3 gives the median bidding ratios for each session and each auction type. The median ratios are higher than the benchmark RNE ratios, which again suggests risk-averse behavior (in the sense of Proposition 2) in our sample. ${ }^{18}$

\begin{tabular}{|c|c|c|c|c|c|c|}
\hline \multirow{2}{*}{ Session } & \multicolumn{6}{|c|}{ median bidding ratio } \\
\cline { 2 - 7 } & \multicolumn{2}{|c|}{$r_{b}(v)$} & \multicolumn{2}{c|}{$r_{h}(v)$} & \multicolumn{2}{c|}{$r_{l}(v)$} \\
\cline { 2 - 7 } & phase 1 & phase 2 & phase 1 & phase 2 & phase 1 & phase 2 \\
\hline \hline 1 & .56 & .62 & .74 & .71 & .39 & .19 \\
\hline 2 & .60 & .66 & .77 & .78 & .41 & .47 \\
\hline 3 & .59 & .47 & .77 & .85 & .43 & .46 \\
\hline 4 & .70 & .81 & .86 & .88 & .44 & .46 \\
\hline 5 & .61 & .68 & .79 & .83 & .45 & .50 \\
\hline 6 & .58 & .55 & .77 & .70 & .46 & .41 \\
\hline \hline all & .61 & .63 & .79 & .80 & .44 & .44 \\
\hline
\end{tabular}

Table 3.3: Median bidding ratios

decision. Tversky and Kahneman (1986), to cite a classic reference, report that $72 \%$ of 126 subjects preferred a certain payoff of 100 over a $50 \%$ chance of obtaining a payoff of 200 . In a recent investigation, Sonsino et al.(2001) find that $69 \%$ of 120 subjects prefer a certain payoff of 107 on a lottery that pays 150 with probability $30 \%, 80$ with probability $40 \%$ and 100 with probability $30 \%$.

${ }^{16}$ For simplification we suppress the agent-index $i$ from the notation for $r$.

${ }^{17}$ The conformity rates for the first phase of the experiment were $72.9 \%$ and $83.3 \%$, respectively; the corresponding rates for the second phase were $86.4 \%$, and $84.1 \%$, respectively. A Wilcoxon test, $N=6$, two-tailed, suggests that the differences in proportions across the two phases are statistically insignificant at $p>0.1$.

${ }^{18}$ The average bidding ratios are much lower than the median ratios because of the underbidding discussed above in this section. 


\subsubsection{Correlation between bids and values}

The coefficients of correlation between the three individual bidding ratios $\left(r_{b}, r_{l}, r_{h}\right)$ and the corresponding realized values were found to be positive and statistically significant at 0.01 for both phases of the experiment. Moreover, the coefficients for the second phase are significantly higher than those for the first phase. ${ }^{19}$ In particular, the Spearman correlation coefficients for the bidding ratio in the one-bid auctions $\left(r_{b}\right)$ were 0.174 (for the first phase of the experiment) and 0.299 (for the second phase). The corresponding coefficients for the high-bidding ratio $\left(r_{h}\right)$ were 0.143 and 0.217 and for the low bidding ratio $\left(r_{l}\right): 0.365$ and 0.410 , respectively. Note that in our benchmark equilibrium model the bidding ratios are constant; this implies zero correlation between bidding ratios and values, a prediction that is violated by the data. The observed positive correlations suggest that subjects tend to bid more aggressively as their realized value increases. Moreover, this inclination increases in the second phase of the experiment.

The correlation between bids and values becomes even more significant when we examine the three Relative Bidding Deviations (see Kagel and Roth, 1992):

$$
\begin{gathered}
R B D_{b}=\frac{b(v)-b^{*}(v)}{v} \\
R B D_{h}=\frac{h(v)-h^{*}(v)}{v} \text { and } R B D_{l}=\frac{l(v)-l^{*}(v)}{v} .
\end{gathered}
$$

The coefficients described in Table 3.4 are positive and statistically significant. Recall that in Kagel and Roth (1992) the coefficients were negative and used to support Harrison's (1989) "flat maximum critique" 20 concerning the experimental evidence with first-price auctions. ${ }^{21}$ The positive coefficients found in the current study may thus be used as counter-evidence to the flat maximum critique and (in this sense) seem to strengthen the weight of our evidence for risk-averse behavior in first-price auctions.

\footnotetext{
${ }^{19}$ Wilcoxon one-tailed test, $p<.05$ for $r_{b}$ and $r_{h}, N=6$. For $r_{l}$, the correlation coefficient in phase 2 is higher than in phase 1 in 4 (out of 6 ) sessions.

${ }^{20}$ Harrison's critique suggests that subjects who have low realized values and thus have low odds of winning the auction have little incentives to bid optimally. See chapter G in Kagel's survey on auctions in the Handbook of Experimental Economics (1995) for more details on this controversy.

${ }^{21}$ Negative correlations between subjects' valuations and the relative bidding ratios were also found by Pezanis-Christou (1998) in his study of asymmetric auctions.
} 


\begin{tabular}{|c|c|c|c|c|c|c|}
\hline \multirow[b]{2}{*}{ Session } & \multicolumn{2}{|c|}{ one-bid } & \multicolumn{2}{|c|}{ two-bid_high } & \multicolumn{2}{|c|}{ two-bid_low } \\
\hline & phase 1 & phase 2 & phase 1 & phase 2 & phase 1 & phase 2 \\
\hline 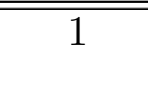 & $\begin{array}{l}319^{* *} \\
(192)\end{array}$ & $\begin{array}{c}618^{* *} \\
(46)\end{array}$ & $\begin{array}{l}402^{* *} \\
(192)\end{array}$ & $\begin{array}{c}470^{* *} \\
(82)\end{array}$ & $\begin{array}{l}.661^{* *} \\
(192)\end{array}$ & $\begin{array}{c}661^{* *} \\
(82)\end{array}$ \\
\hline 2 & $\begin{array}{l}.275^{* *} \\
(192)\end{array}$ & $\begin{array}{c}.522^{* *} \\
(28)\end{array}$ & $\begin{array}{l}.328^{* *} \\
(192)\end{array}$ & $\begin{array}{l}.466^{* *} \\
(100)\end{array}$ & $\begin{array}{l}.544^{* *} \\
(192)\end{array}$ & $\begin{array}{l}.536^{* *} \\
(100)\end{array}$ \\
\hline 3 & $\begin{array}{l}.296^{* *} \\
(192)\end{array}$ & $\begin{array}{c}.395^{* *} \\
(44)\end{array}$ & $\begin{array}{l}.187^{* *} \\
(192)\end{array}$ & $\begin{array}{l}.321^{* *} \\
(84)\end{array}$ & $\begin{array}{l}335^{* *} \\
(192)\end{array}$ & $\begin{array}{l}.239^{*} \\
(84)\end{array}$ \\
\hline 4 & $\begin{array}{l}.456^{* *} \\
(192)\end{array}$ & $\begin{array}{c}.851^{* *} \\
(42)\end{array}$ & $\begin{array}{l}.301^{* *} \\
(192)\end{array}$ & $\begin{array}{c}.423^{* *} \\
(86)\end{array}$ & $\begin{array}{l}376^{* *} \\
(192)\end{array}$ & $\begin{array}{l}.406^{* *} \\
(86)\end{array}$ \\
\hline 5 & $\begin{array}{l}.172^{*} \\
(192)\end{array}$ & $\begin{array}{c}.194 \\
(32)\end{array}$ & $\begin{array}{l}.281^{* *} \\
(192)\end{array}$ & $\begin{array}{c}.601^{* *} \\
(96)\end{array}$ & $\begin{array}{l}.313^{* *} \\
(192)\end{array}$ & $\begin{array}{c}.644^{* *} \\
(96)\end{array}$ \\
\hline 6 & $\begin{array}{l}.428^{* *} \\
(192)\end{array}$ & $\begin{array}{l}.830^{* *} \\
(10)\end{array}$ & $\begin{array}{l}.370^{* *} \\
(192)\end{array}$ & $\begin{array}{l}.394^{* *} \\
(118)\end{array}$ & $\begin{array}{l}.539^{* *} \\
(192)\end{array}$ & $\begin{array}{l}.641^{* *} \\
(118)\end{array}$ \\
\hline 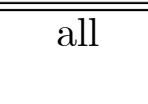 & $\begin{array}{l}.312^{* *} \\
(1152)\end{array}$ & $\begin{array}{l}.477^{* *} \\
(202)\end{array}$ & $\begin{array}{l}302^{* *} \\
(1152)\end{array}$ & $\begin{array}{l}.427^{* *} \\
(566)\end{array}$ & $\begin{array}{l}.462^{* *} \\
(1152)\end{array}$ & $\begin{array}{l}.521^{* *} \\
(566)\end{array}$ \\
\hline
\end{tabular}

Table 3.4: Spearman correlation coefficients: RBDs and values (number of RBDs in brackets)
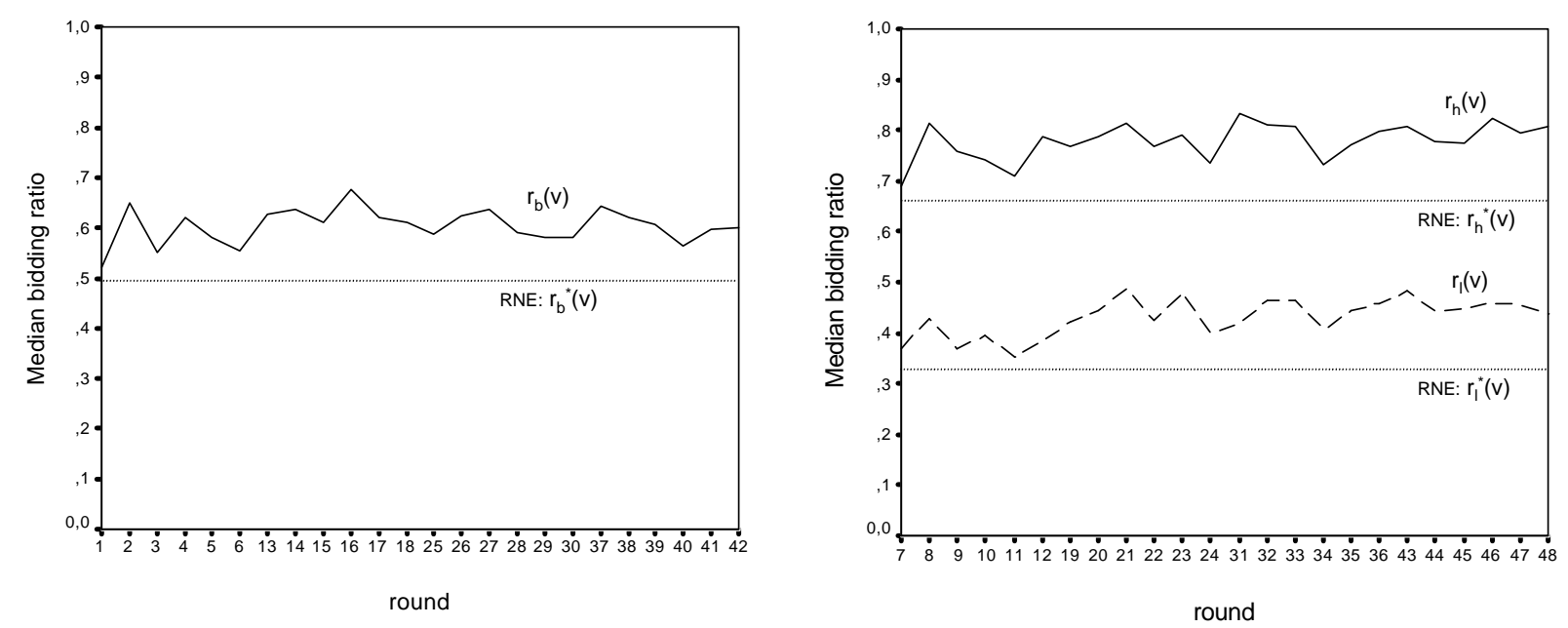

Figure 3.1: Time paths of median bidding ratios (phase 1)

\subsubsection{Dynamics}

Figure 3.1 describes the changes in median bidding ratios in the 48 rounds of the first phase of the experiment. The rather flat lines suggest that subjects' behavior does not change 
in any specific direction across these rounds. Furthermore, the results of a Spearman correlation analysis between the relative bidding deviations (RBDs) at each round $t$ and the corresponding round index $t$ disclose no clear-cut trends; the correlation coefficients are both, positive and negative, and in almost all cases insignificant. Overall it seems that our subjects did not significantly modify their behavior during the experiment.

It is still interesting, however, to check whether the information-feedback provided to the subjects at the end of each round generated some consistencies in subjects' behavior. Table 3.5 presents the proportion of cases where subjects' behavior matched the following two heuristics:

Heuristic 1: "Increase your bidding ratio after losing the current auction"

Heuristic 2: "Decrease your bidding ratio after winning the current auction," in each phase of the experiment. ${ }^{22}$

\begin{tabular}{|c|c|c|c|c|c|c|}
\hline & \multicolumn{2}{|c|}{ one-bid } & \multicolumn{2}{c|}{ two-bid_high } & \multicolumn{2}{c|}{ two-bid_low } \\
\cline { 2 - 7 } & phase 1 & phase 2 & phase 1 & phase 2 & phase 1 & phase 2 \\
\hline \hline Heuristic 1 & $63 \%$ & $75 \%$ & $57 \%$ & $60 \%$ & $59 \%$ & $57 \%$ \\
\hline Heuristic 2 & $62 \%$ & $65 \%$ & $57 \%$ & $58 \%$ & $58 \%$ & $56 \%$ \\
\hline
\end{tabular}

Table 3.5: Proportion of cases where subjects followed each heuristic

Table 3.5 shows that the proportion of cases where subjects conformed to heuristic 1 when playing one-bid auctions was $63 \%$ in the first phase of the experiment. The proportion for the second phase of the experiment was much higher, $75 \%$, but recall that the sample size for this case was relatively low (only 101 one-bid auctions). The corresponding conformity rates for heuristic 2 were above $60 \%$ in both phases of the experiment. The conformity rates for the bids submitted in two-bid auctions were slightly lower; however still close to $60 \%$ and always higher than $50 \%$ in all sessions but one. The proportions for the second phase of the experiment were not significantly different from those obtained for the first phase of the experiment. ${ }^{23}$

\footnotetext{
${ }^{22}$ The motivation for studying such heuristics may also follow from the learning direction theory applied to the context of auctions (see Selten and Buchta, 1998, and Güth, 1998).

${ }^{23}$ Wilcoxon test, $p>.625, N=6$, two-tailed.
} 


\subsubsection{Estimation}

This section briefly describes the results of an estimation of the equilibrium benchmark models presented in Section 2.

To decide on the appropriate level of estimation (a separate estimation for each subject vs. an aggregate estimation over all subjects) we use the nonparametric Kruskal-Wallace $H$ test for heterogeneity across samples. Formally, for each session and for each type of bid using the data from the first phase of the experiment, we separately test the null hypothesis that the eight (number of subjects per session) vectors of observed deviations from the risk neutral equilibrium predictions represent eight samples from the same population. ${ }^{24}$ The null hypothesis is strongly rejected $(p<0.001)$ for all 6 sessions and for all 3 types of bids (one-bid, low-bid and high-bid).

Given this result we prefer to estimate an asymmetric model that acknowledges the heterogeneity across subjects. However, direct estimation of the CRRAM equations (see Proposition 5) for each subject seems to require exceptional technical effort. ${ }^{25}$ We, therefore, choose to estimate a system of three linear bid functions using the seemingly unrelated regressions estimation technique (SURE).${ }^{26}$ Given the fact that the same individual submitted three different types of bids, the disturbances in the three equations (at a given time) are likely to reflect some common unmeasurable factors, and hence could be correlated.

In particular, we estimate the following system of three linear equations on the normalized data for each subject $i$ :

$$
\begin{aligned}
& b_{i}=\beta_{0 i}^{b}+\beta_{1 i}^{b} \cdot v_{i}^{\text {one-bid }}+\epsilon_{i}^{b} \\
& h_{i}=\beta_{0 i}^{h}+\beta_{1 i}^{h} \cdot v_{i}^{t w o-b i d}+\epsilon_{i}^{h}
\end{aligned}
$$

\footnotetext{
${ }^{24}$ The vector's dimension is 192; the number of auctions of each type in the first phase of the experiment is 24 .

${ }^{25}$ See, for example, the heavy computation required to estimate the CRRAM model for standard onebid auctions in Chen and Plott (1998).

${ }^{26}$ For a formal presentation of the SURE model see, e.g., Judge et al.(1988), pp. 443-466.
} 


$$
l_{i}=\beta_{0 i}^{l}+\beta_{1 i}^{l} \cdot v_{i}^{t w o-b i d}+\epsilon_{i}^{l}
$$

where $\epsilon_{i}^{b}, \epsilon_{i}^{l}$ and $\epsilon_{i}^{h}$ represent the noise in each equation and the variance-covariance matrix of the three noise-variables may take an arbitrary (non-diagonal) form. ${ }^{27}$

Figure B.3 in Appendix B describes the distribution of the $R^{2}$ of the estimated equations. The fit of the linear approximations is quite good. The median value of $R^{2}$ is 0.899 . Only for about $8 \%$ of the subjects do the explanatory variables $\left(v_{i}\right)$ explain less than $70 \%$ of the variation in all three bids. For about $70 \%$ of the subjects, however, the explanatory variables explain over $81 \%$ of the bids variation.

\begin{tabular}{|c|c|c|c|c|c|c|c|}
\hline \multirow[b]{2}{*}{ Session } & \multirow{2}{*}{$\begin{array}{c}\text { Nr. of } \\
\text { subjects }\end{array}$} & \multicolumn{3}{|c|}{ number of $\hat{\beta}_{0 i}^{j}$ sign. $\neq 0$} & \multicolumn{3}{|c|}{ number of $\hat{\beta}_{0 i}^{j}<0$} \\
\hline & & $\hat{\beta}_{0 i}^{b}$ & $\hat{\beta}_{0 i}^{h}$ & $\hat{\beta}_{0 i}^{l}$ & $\hat{\beta}_{0 i}^{b}$ & $\hat{\beta}_{0 i}^{h}$ & $\hat{\beta}_{0 i}^{l}$ \\
\hline 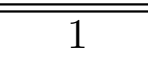 & 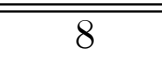 & $\begin{array}{ll}5 & (63 \%)\end{array}$ & $\begin{array}{ll}5 & (63 \%)\end{array}$ & $\begin{array}{ll}8 \quad(100 \%) \\
\end{array}$ & $7 \overline{7 \quad(88 \%)}$ & $7 \overline{7 \quad(88 \%)}$ & $\begin{array}{cc}8 \quad(100 \%) \\
\end{array}$ \\
\hline 2 & 8 & $\begin{array}{ll}3 & (38 \%) \\
\end{array}$ & $1 \quad(13 \%)$ & $6 \quad(75 \%)$ & $4 \quad(50 \%)$ & $6 \quad(75 \%)$ & $7 \quad(88 \%)$ \\
\hline 3 & 8 & $\begin{array}{ll}3 & (38 \%)\end{array}$ & $2 \quad(25 \%)$ & $4 \quad(50 \%)$ & $\begin{array}{ll}7 & (88 \%)\end{array}$ & $4 \quad(50 \%)$ & $7 \quad(88 \%)$ \\
\hline 4 & 8 & $1 \quad(13 \%)$ & $\begin{array}{ll}3 & (38 \%)\end{array}$ & $3 \quad(38 \%)$ & $\begin{array}{ll}6 & (75 \%)\end{array}$ & $3 \quad(38 \%)$ & $6 \quad(75 \%)$ \\
\hline 5 & 8 & $1 \quad(13 \%)$ & $0 \quad(0 \%)$ & $2 \quad(25 \%)$ & $3 \quad(38 \%)$ & $4 \quad(50 \%)$ & $5 \quad(63 \%)$ \\
\hline 6 & 8 & $3 \quad(38 \%)$ & $5 \quad(63 \%)$ & $5 \quad(63 \%)$ & $7 \quad(88 \%)$ & $5 \quad(63 \%)$ & $8 \quad(100 \%)$ \\
\hline all & 48 & $16(33 \%)$ & $16(33 \%)$ & $28(58 \%)$ & $34(71 \%)$ & $\begin{array}{ll}29 \quad(60 \%) \\
\end{array}$ & $41 \quad(85 \%)$ \\
\hline \multirow[b]{2}{*}{ Session } & \multirow{2}{*}{$\begin{array}{c}\text { Nr. of } \\
\text { subjects }\end{array}$} & \multicolumn{3}{|c|}{ "number of significant } & \multicolumn{3}{|c|}{ "number of } \\
\hline & & $\hat{\beta}_{1 i}^{b} \neq \frac{1}{2}$ & $\hat{\beta}_{1 i}^{h} \neq \frac{2}{3}$ & $\hat{\beta}_{1 i}^{l} \neq \frac{1}{3}$ & $\hat{\beta}_{1 i}^{b}>\frac{1}{2}$ & $\hat{\beta}_{1 i}^{h}>\frac{2}{3}$ & $\hat{\beta}_{1 i}^{l}>\frac{1}{3}$ \\
\hline$\overline{1}$ & 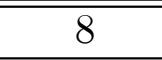 & $\begin{array}{l}5 \quad(63 \%) \\
\end{array}$ & $7 \quad 7 \quad(88 \%)$ & $8 \quad(100 \%)$ & $\begin{array}{cc}8 \quad(100 \%) \\
\end{array}$ & $7 \quad(88 \%)$ & $\begin{array}{ll}8 \quad(100 \%) \\
\end{array}$ \\
\hline 2 & 8 & $4 \quad(50 \%)$ & $\begin{array}{ll}7 & (88 \%)\end{array}$ & $7 \quad(88 \%)$ & $6 \quad(75 \%)$ & $6 \quad(75 \%)$ & $7 \quad(88 \%)$ \\
\hline 3 & 8 & $5 \quad(63 \%)$ & $5 \quad(63 \%)$ & $6 \quad(75 \%)$ & $7 \quad(88 \%)$ & $\begin{array}{ll}7 & (88 \%)\end{array}$ & $8 \quad(100 \%)$ \\
\hline 4 & 8 & $7 \quad(88 \%)$ & $6 \quad(75 \%)$ & $7 \quad(88 \%)$ & $8 \quad(100 \%)$ & $7 \quad(88 \%)$ & $8 \quad(100 \%)$ \\
\hline 5 & 8 & $6 \quad(75 \%)$ & $4 \quad(50 \%)$ & $6 \quad(75 \%)$ & $7 \quad(88 \%)$ & $\begin{array}{ll}5 & (63 \%)\end{array}$ & $7 \quad(88 \%)$ \\
\hline 6 & 8 & $\begin{array}{ll}7 & (88 \%) \\
\end{array}$ & $\begin{array}{ll}5 & (63 \%) \\
\end{array}$ & $8 \quad(100 \%)$ & $8 \quad(100 \%)$ & $\begin{array}{ll}6 & (75 \%) \\
\end{array}$ & $8 \quad(100 \%)$ \\
\hline "all & $\overline{448}$ & $34(71 \%)$ & $34(71 \%)$ & $42 \quad(88 \%)$ & $44(92 \%)$ & 38 (79\%) & $\begin{array}{c}46 \quad(96 \%) \\
\end{array}$ \\
\hline
\end{tabular}

Table 3.6: Summary of regression estimates $\left(\hat{\beta}_{0 i}^{j}, \hat{\beta}_{1 i}^{j}\right)$

\footnotetext{
${ }^{27}$ To test the underlying assumption that the variance-covariance matrix of the noise terms is indeed non-diagonal we use the Lagrange multiplier statistic, suggested by Breusch and Pagan (1980). For the current application, the statistic is $\lambda=T\left(r_{12}^{2}+r_{13}^{2}+r_{23}^{2}\right)$ where $r_{i j}^{2}\left(=\frac{\hat{\sigma}_{i j}^{2}}{\hat{\sigma}_{i i} \hat{\sigma}_{j j}}\right)$ is the squared correlation and $T$ is the number of auctions. Under $H_{0}: \sigma_{12}=\sigma_{13}=\sigma_{23}=0, \lambda$ has an asymptotic $\chi^{2}$-distribution with 3 degrees of freedom. Therefore, the null hypothesis is rejected if $\lambda>7.81473$ (the critical value from a $\chi_{(3)}^{2}$-distribution at $5 \%$ significance level). This condition is satisfied for $65 \%$ (31 out of 48 ) of the subjects.
} 
Table 3.6 summarizes the estimation results. For 7 of the 48 subjects (15\%) all three estimated intercepts, $\hat{\beta}_{0 i}^{b}, \hat{\beta}_{0 i}^{l}$, $\hat{\beta}_{0 i}^{h}$, are significantly different from zero. The intercepts for the one-bid auctions [i.e., the intercepts for equation (3.24)] are negative in $71 \%$ of the cases. $^{28}$ The corresponding proportions of negative intercepts for the high-bid equation (3.24) and low-bid equation (3.25) are $60 \%$ and $85 \%$, respectively. A possible explanation for the negative intercepts might be found in the observed phenomena of "bargain-bidding" discussed earlier in this section.

The estimation results for the slopes reconfirm our previous findings on subjects' inclination for risk-averse behavior. For almost half of the subjects (22 out of 48 subjects) all three slopes $\hat{\beta}_{1 i}^{b}, \hat{\beta}_{1 i}^{l}$ and $\hat{\beta}_{1 i}^{h}$ were significantly higher than the corresponding equilibrium benchmarks for risk-neutral agents. Moreover, in the one-bid auctions $71 \%$ of the estimated slopes were significantly higher than the risk-neutral level. The corresponding proportions for the two-bid auctions were $69 \%$ (for the high-bids) and $88 \%$ (for the low-bids).

\subsection{Efficiency}

We say that an auction allocation is efficient if the bidder with the highest value wins the auction. Overall, the proportions of inefficient one-bid auctions (15.3\% for phase 1 and $16.8 \%$ for phase 2 ) are considerably higher than the corresponding proportions $(10.2 \%$, $12.0 \%$, respectively) for the two-bid auctions.

To further analyze the efficiency of each auction type we define the Efficiency Ratio $(E R)$

$$
E R=\frac{v_{\text {buyer }}}{\max \left\{v_{1}, v_{2}\right\}}
$$

where $v_{\text {buyer }}$ denotes the valuation of the winner.

Note that the efficiency ratio equals 1 when the auction is won by the bidder with the highest valuation; however, the ratio is lower than one when the auction is inefficient

\footnotetext{
${ }^{28}$ For comparison, note that Cox et al.(1988) find significant intercepts for 34 of 156 subjects (21.8\%) and negative intercepts for $62.8 \%$ of the subjects in the standard first-price auction.
} 
and it is monotonically decreasing with the gap between the highest valuation and the valuation of the buyer. Table 3.7 gives the average efficiency ratios for each auction.

\begin{tabular}{|c|c|c|c|c|}
\hline \multirow{2}{*}{ Session } & \multicolumn{2}{|c|}{ phase 1 } & \multicolumn{2}{c|}{ phase 2} \\
\cline { 2 - 5 } & one-bid & two-bid & one-bid & two-bid \\
\hline \hline 1 & 97.5 & 98.1 & 98.6 & 98.3 \\
\hline 2 & 97.8 & 98.7 & 99.2 & 98.9 \\
\hline 3 & 97.7 & 98.6 & 96.7 & 99.0 \\
\hline 4 & 98.8 & 98.6 & 99.4 & 99.5 \\
\hline 5 & 97.4 & 98.8 & 96.9 & 99.4 \\
\hline 6 & 98.2 & 98.8 & 99.5 & 98.1 \\
\hline \hline all & 97.9 & 98.6 & 98.2 & 98.8 \\
\hline
\end{tabular}

Table 3.7: Mean efficiency ratios, ER, (in \%)

Again, the observed efficiency is (slightly) higher in the two-bid auction compared to one-bid auction in both phases of the experiment. A Wilcoxon test suggests that the difference is statistically significant in the first phase ( $p=0.031, N=6$, one-tailed). Efficiency increases slightly for both auction types in the second phase. The difference in favor of the two-bid auction, however, is no longer significant.

\subsection{Prices and payoffs}

The average prices collected by the seller in each auction are presented in Table 3.8. The average prices obtained in the first phase of the experiment are quite similar across the two mechanisms. In the second phase, the one-bid auction seems to produce slightly higher prices but the differences are statistically insignificant (Wilcoxon test, $p=.219(.156)$, for the first (second) phase, $N=6$, two-tailed). Additional tests confirm that there are no significant differences between the cumulative distributions of prices (see Figure B.2 in Appendix B) and the average prices obtained in each block of the experiment, across the two auction types. 


\begin{tabular}{|c|c|c|c|c|}
\hline \multirow{2}{*}{ Session } & \multicolumn{2}{|c|}{ 1. phase } & \multicolumn{2}{c|}{ 2. phase } \\
\cline { 2 - 5 } & one-bid & two-bid & one-bid & two-bid \\
\hline \hline 1 & $91.22(18.54)$ & $86.70(21.79)$ & $91.09(21.52)$ & $81.32(23.15)$ \\
\hline 2 & $89.83(17.26)$ & $89.03(22.61)$ & $101.71(17.59)$ & $89.20(25.51)$ \\
\hline 3 & $90.47(21.40)$ & $94.29(20.47)$ & $89.36(15.91)$ & $91.48(17.16)$ \\
\hline 4 & $96.50(19.05)$ & $94.01(22.58)$ & $104.14(24.58)$ & $94.05(18.85)$ \\
\hline 5 & $92.43(18.34)$ & $91.14(18.40)$ & $95.50(14.05)$ & $88.04(18.46)$ \\
\hline 6 & $96.43(19.80)$ & $87.57(18.66)$ & $86.60(18.00)$ & $90.07(19.96)$ \\
\hline \hline all & $92.81(19.26)$ & $90.46(20.99)$ & $95.38(20.13)$ & $89.12(21.00)$ \\
\hline
\end{tabular}

Table 3.8: Mean prices (std. deviation)

The average payoffs of the winning bidder in each auction type in the first phase of the experiment are displayed in Table 3.9. Again, the results reveal no significant differences across the two mechanisms (Wilcoxon test, $p=.156, N=6$, two-tailed). Note, however, that the standard deviation is significantly higher in the two-bid auction (Binomial test, $p=.031, N=6$, two-tailed). Overall the results suggest that (on average) the experience gained with the two mechanisms during the first phase of the experiment did not provide a strong reason to prefer one of the two auction types in the second phase of the experiment. The similarity in average payoffs is maintained in the second phase of the experiment. ${ }^{29}$

\begin{tabular}{|c|c|c|c|c|c|c|c|}
\hline Session & 1 & 2 & 3 & 4 & 5 & 6 & all \\
\hline \hline one-bid & 12.37 & 12.33 & 11.43 & 9.30 & 10.57 & 11.52 & 11.25 \\
& $(16.39)$ & $(15.86)$ & $(16.86)$ & $(12.59)$ & $(15.73)$ & $(16.60)$ & $(15.74)$ \\
\hline two-bid & 13.31 & 11.83 & 12.70 & 9.22 & 13.63 & 13.82 & 12.42 \\
& $(17.83)$ & $(18.12)$ & $(18.74)$ & $(17.22)$ & $(19.34)$ & $(18.16)$ & $(18.27)$ \\
\hline
\end{tabular}

Table 3.9: Average payoffs in phase 1 (std. deviation)

\subsection{Choice of mechanism}

Recall that in the second phase of the experiment subjects could choose their favorite auction type before observing their realized value. Table 3.10 gives the distribution of choices for each session. Altogether, subjects preferred the two-bid auction in 516 out of 672 cases $(77 \%)$. Moreover, subjects' strong preference for the two-bid auction holds in all 6 sessions.

\footnotetext{
${ }^{29}$ Wilcoxon test, $p=.219, N=6$, two-tailed.
} 


\begin{tabular}{|c|c|c|c|c|c|c|c|}
\hline Session & 1 & 2 & 3 & 4 & 5 & 6 & all \\
\hline \hline one-bid & $33 \%$ & $21 \%$ & $31 \%$ & $28 \%$ & $21 \%$ & $6 \%$ & $23 \%$ \\
\hline two-bid & $67 \%$ & $79 \%$ & $69 \%$ & $72 \%$ & $79 \%$ & $94 \%$ & $77 \%$ \\
\hline
\end{tabular}

Table 3.10: Auction selection proportions (phase 2)

This strong result is confirmed by the data at the individual level. Recall that each subject was allowed to choose his favorite auction type in 14 rounds (and acted as the balancing player at the other 2 rounds). Figure 3.2 demonstrates that an overwhelming majority $(77 \%)$ of the participants chose the two-bid auction at least 9 times.

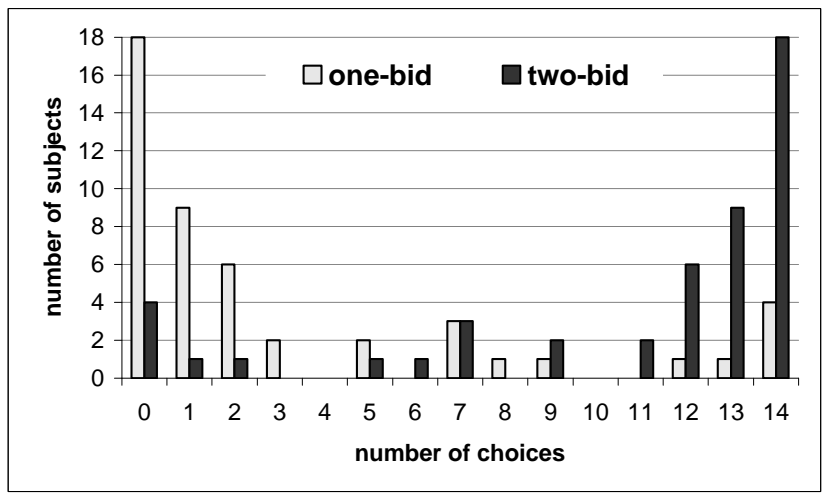

Figure 3.2: Distribution of subjects' choices

A closer inspection of the data suggests that 15 of our 48 subjects (31\%) chose the twobid auction in more than 7 of their 14 choice-rounds, in spite of the fact that their average profits in the two-bid auction was lower or approximately equal ${ }^{30}$ to the average profits in the one-bid auction in the first phase of the experiment. The 24 subjects that had a profitable experience with the two-bid mechanism during the first phase of the experiment, chose, on average, the two-bid auction in 12 of the 14 rounds.

Furthermore, when we count the number of cases (in the second phase of the experiment) where: (i) a subject that lost a two-bid auction chose the same auction type in the following round or (ii) a subject that won a one-bid auction chose the two-bid auction in

\footnotetext{
${ }^{30}$ We say that the profits were approximately equal when the difference in average payoffs was not bigger than 1 .
} 
the following round, we find that in 197 out of 246 cases (80\%) subjects who had plausible reasons to select the one-bid auction voted for the two-bid auction.

One possible explanation for this result is provided by our benchmark equilibrium model. The model suggests that when subjects act risk-aversively: (1) their bidding ratios would be higher than the ones corresponding to the RNE and (2) their expected utility from the two-bid auction would be higher than the corresponding utility from the one-bid auction (for each value $v$ ). Our data would seem to fit these predictions in both dimensions.

Alternatively, one might invoke a context-dependent preferences type of argument to explain the results. In particular, one might suggest that the two-bid mechanism is perceived as more exciting than the standard one-bid auction. A variation on Conlisk's (1993) idea, for instance, would suggest that subjects that exhibit an "extra tiny utility" from the possibility to place two different bids might prefer the two-bid mechanism over the standard one-bid auction, as demonstrated in our data-set.

Finally one might suggest that the two-bid auction is perceived as easier to solve than the one-bid auction. In particular, note that in the standard one-bid case, a submitted bid not only determines the probability of winning but also represents at the same time the price the bidder is willing to pay for the object. In the two-bid case the bidders have two separate decision parameters. The probability of winning is determined by the high-bid alone. The actual price paid by the bidder upon winning, however, might also depend on the low-bid. This suggests that bidders might find the two-bid auction a cognitively easier problem to solve and thus reveal strong preferences for this mechanism.

\section{Concluding discussion}

The constant increase in economic activity through the Web provides a serious challenge to basic economic research. Economic transactions on the Web might be quite different in many respects from the corresponding transactions in traditional environments. The costs of conducting an auction on the Web, for instance, seem marginal compared to the costs 
of running the auction in a real auction house. Indeed, some of the largest auction-sites on the Web (e.g., Ebay, Yahoo, City auction) act as listing-sites (Lucking-Reiley, 1999) through which potential sellers may auction their merchandise with relatively low cost and effort. Note also that it is quite inexpensive to modify a given auction mechanism when the auction is mounted on the Web. A shift from using a one-bid auction to implementing a two-bid auction, for instance, seems like a technically trivial problem that should not impose any significant costs on the auctioneer. These conveniences of running auctions on the Web, together with the "global market" effect and the intensified competition on the electronic medium bring up the conjecture that sellers might compete at the level of the auction mechanism; i.e., try to find the mechanism that attracts the most bidders and generates the highest revenue for the seller. Indeed, Monderer and Tennenholtz (1998) study an auction-selection game where multiple sellers of an homogeneous good compete for a given pool of buyers. Sellers may choose different auction mechanisms (first-price, second-price and in general k-th price auction); buyers choose their favorite auctionsites accordingly. Monderer and Tennenholtz investigate the equilibria of the underlying games and show that the optimal auction mechanism depends on the risk preferences of the potential bidders.

With this as a general motivation for comparative studies of different auction mechanisms on the Web, this paper focuses on a comparative experimental investigation of the one-bid and two-bid first-price auctions. We show that (in both auction types) subjects typically act as if they are risk-averse, in the sense of bidding more than the Nash equilibria for riskneutral agents and in the sense of preferring the two-bid auction over the one-bid auction when given the possibility to select among the two. The average profits to the buyer and the average prices collected by the seller, however, were not significantly different across the two-mechanisms.

A closer inspection of the data shows that the individual bidding ratios (and the individual relative deviations from the risk neutral equilibrium bidding strategies) tend to increase 
with the buyers' realized values. In this sense, buyers tend to bid more aggressively as their realized values increases. Subjects also reveal a robust inclination to bid less than the minimal possible valuation; a phenomenon that we term "bargain-bidding". An inspection of the dynamics of play suggests that subjects do not modify their behavior significantly during the experiment. However, we find some inclination to follow intuitively appealing behavioral heuristics; i.e., increase the bidding ratio after losing an auction and decrease it after winning an auction.

\section{References}

[1] Breusch, T. S. and A. R. Pagan (1980): The Lagrange Multiplier test and its applications to model specification in econometrics, Review of Economic Studies, 47, 239-254.

[2] Chen, K.-Y. and C. R. Plott (1998): Nonlinear behavior in sealed bid first-price. auctions, Games and Economic Behavior, 25, 34-78.

[3] Conlisk (1993): The Utility of Gambling. Journal of Risk and Uncertainty, 255-275.

[4] Cox, J. C., B. Roberson, and V. L. Smith (1982): Theory and behavior of single object auctions, in: Research in experimental economics, Vernon L. Smith, ed., Greenwich, Conn.: JAI Press, Vol.2, 1-43.

[5] Coppinger, V. M., V. L. Smith, and J. A. Titus (1980): Incentives and behavior in English, Dutch and sealed-bid auctions, Economic Inquiry, 43, 1-22.

[6] Cox, J. C., V. L. Smith, and J. M. Walker (1985): Experimental development of sealed-bid auction theory: Calibrating controls for risk aversion, American Economic Review, Papers and Proceedings, 75, 160-65.

[7] Cox, J. C., V. L. Smith, and J. M. Walker (1988): Theory and individual behavior of first-price auctions, Journal of Risk and Uncertainty, 1, 61-99. 
[8] Cox, J. C., V. L. Smith, and J. M. Walker (1992): Theory and misbehavior in firstprice auctions: Comment, 1992, American Economic Review, 82/5, 1392-412.

[9] Fischbacher, U. (1998): z-Tree: Zurich Toolbox For Readymade Economic Experiments, Zurich University.

[10] Güth, W. (1998): On the effects of the pricing rule in auctions and fair division games - an experimental study, in: D. Budescu, I. Erev, and R. Zwick (eds.), Games and Human Behavior, Mahwah (N.J.): Lawrence Erlbaum Ass.

[11] Güth, W., R. Ivanova-Stenzel, M. Königstein, and M. Strobel (1999): Auctions and Fair Division Games Under Different Price Rules: Individual Bid Functions, Prices and Efficiency Rates, Discussion Paper, Sonderforschungsbereich 373, Humboldt University at Berlin, 101/1999.

[12] Güth, W., R. Ivanova-Stenzel, E. Wolfstetter (2001): Bidding Behavior in Asymmetric Auctions: An Experimental Study, Discussion Paper, Sonderforschungsbereich 373, Humboldt University at Berlin.

[13] Harrison, G. W. (1989): Theory and misbehavior of first-price auctions, American Economic Review, 79/4, 749-62.

[14] Holt, C. A. (1980): Competitive bidding for contracts under alternative auction procedures, Journal of Political Economy, 88, 433-45.

[15] Judge, G. G., R. C Hil, W. E Griffiths, H. Lütkepohl, and T.-C. Lee (1988): Introduction to the theory and practice of econometrics, 2nd edition, John Wiley \& Sons, New York, 443-466.

[16] Kagel, J. H. (1995): Auctions: A survey of Experimental Research, in: J. Kagel and A. R. Roth (eds), The Handbook of Experimental Economics, Princeton (N.J.): Princeton University Press 
[17] Kagel, J. H., R. M. Harstad and D. Levin (1987): Information impact and allocation rules in auctions with affiliated private values: A laboratory study, Econometrica, 55: $1275-1304$.

[18] Kagel, J. H. and D. Levin, (1985): Individual bidder behavior in first-price private value auctions, Economic Letters, 19, 125-28.

[19] Kagel, J. H. and D. Levin, (1993): Independent private value auctions: Bidder behavior in first-, second- and third-price auctions with varying numbers of bidders, The Economic Journal, 103, 868-79.

[20] Kagel, J. H. and A. E. Roth (1992): Theory and misbehavior in first-price auctions: Comment, American Economic Review, 82/5, 1379-91.

[21] Lucking-Reiley, D. (1999): Auctions on the Internet: What's being auctioned and How?. Journal of Industrial Economics, 48, No. 3, 227-252.

[22] Meyerson, R. B. (1981): Optimal auction design, Mathematics of Operations Research, 6, 58-73.

[23] Monderer, D. and Tennenholtz, M. (1998): Internet Auctions - Are They Gamblers Attraction?. Mimeo, Technion.

[24] Pezanis-Christou, P. (1999): On the Impact of Low-Balling: Experimental Results in Asymmetric Auctions, mimeo: Laboratory for Experimental Economics, University of Bonn

[25] Riley, J. G. and W. F. Samuelson (1981): Optimal Auctions, American Economic Review,71/3, 381-92.

[26] Selten, R. and J. Buchta (1998): Experimental sealed bid first-price. auction with directly observed bid functions, in: D. Budescu, I. Erev, and R. Zwick (eds.), Games and Human Behavior, Mahwah (N.J.): Lawrence Erlbaum Ass. 
[27] Sonsino, D, Mador, G and U. Benzion (2000): The Complexity Effects on Choice with Uncertainty - Experimental Evidence, Discussion Paper nu 99-14, Monaster center for Economic Research, Ben-Gurion University of the Negev.

[28] Tversky A. and Kahneman, D. (1986): Rational choice and the framing of decisions, Journal of Business, 59, 251-278.

[29] Vickrey, W. (1961): Counterspeculation, auctions, and competitive sealed tenders, Journal of Finance, 16, 8-37. 


\section{Appendix A:}

\section{Proof of propositions}

First we derive the equilibrium strategies presented in Proposition 1.

We start with the two-bid model.

Assume a symmetric equilibrium $h(\cdot), l(\cdot)$ where both bidding functions are strictly increasing and continuous. Let $h^{-1}(\cdot)$ and $l^{-1}(\cdot)$ denote the corresponding inverse functions. Let $v$ denote the realized value of bidder $i$.

Let $y \equiv l(v)$ and $z \equiv h(v)$ denote the corresponding equilibrium bids.

Note that the probability that $i$ 's lowest bid would win is equal to

$$
\operatorname{Prob}\left[h\left(v_{j}\right)<y\right]=\operatorname{Prob}\left[V_{j}<h^{-1}(y)\right]=h^{-1}(y)
$$

Similarly, the probability that $i$ 's high-bid would be highest is equal to

$$
\begin{gathered}
\operatorname{Prob}\left[y \leq h_{j}\left(v_{j}\right) \leq z\right]= \\
\left.\operatorname{Prob}\left[h^{-1}(y)\right] \leq V_{j} \leq h^{-1}(z)\right]=h^{-1}(z)-h^{-1}(y)
\end{gathered}
$$

Assuming the utility function $u(x)=x^{\alpha}$, the expected utility of player $i$ equals

$$
\text { (1) } h^{-1}(y) \cdot[v-y]^{\alpha}+\left[h^{-1}(z)-h^{-1}(y)\right] \cdot[v-z]^{\alpha}
$$

Differentiating (1) with respect to $y$ gives the first order condition:

$$
\begin{gathered}
(2)-\alpha[v-y]^{\alpha-1} \cdot h^{-1}(y)+[v-y]^{\alpha} \cdot \frac{d}{d(y)} h^{-1}(y) \\
-[v-z]^{\alpha} \cdot \frac{d}{d(y)} h^{-1}(y)=0
\end{gathered}
$$

Differentiating (1) with respect to $z$ gives the first order condition:

$$
-\alpha[v-z]^{\alpha-1} \cdot\left[h^{-1}(z)-h^{-1}(y)\right]+[v-z]^{\alpha} \cdot \frac{d}{d(z)} h^{-1}(z)=0
$$


That is,

$$
\text { (3) }-\alpha \cdot\left[h^{-1}(z)-h^{-1}(y)\right]+[v-z] \cdot \frac{d}{d(z)} h^{-1}(z)=0
$$

Note, however, that

$$
\begin{aligned}
& \text { (4) } \frac{d}{d(y)} h^{-1}(y)=\frac{1}{h^{\prime}(y)} \\
& \text { (5) } \frac{d}{d(z)} h^{-1}(z)=\frac{1}{h^{\prime}(z)}
\end{aligned}
$$

Substituting (4) and (5) into (2) and (3) yields:

$$
\begin{gathered}
(6)-\alpha[v-y]^{\alpha-1} \cdot h^{-1}(y)+[v-y]^{\alpha} \cdot \frac{1}{h^{\prime}(y)}-[v-z]^{\alpha} \cdot \frac{1}{h^{\prime}(y)}=0 \\
(7) \quad-\alpha \cdot\left[h^{-1}(z)-h^{-1}(y)\right]+[v-z] \cdot \frac{1}{h^{\prime}(z)}=0
\end{gathered}
$$

Trying

$$
\text { (8) } y=L(\alpha) \cdot v \quad \text { and } \quad z=H(\alpha) \cdot v
$$

in (6) and (7) gives

$$
L(\alpha)=\frac{1-\left[\frac{\alpha}{1+\alpha}\right]^{\alpha}}{1+\alpha-\left[\frac{\alpha}{1+\alpha}\right]^{\alpha}} \quad \text { and } \quad H(\alpha)=\frac{1+\alpha L}{1+\alpha} .
$$

Direct calculations show that the Hessian matrix of the objective (1) is negative semi definite so that

$$
\text { (9) } \quad l(v)=L(\alpha) \cdot v \quad \text { and } \quad h(v)=H(\alpha) \cdot v
$$

is a symmetric equilibrium of the two-bid auction.

Consider next the one-bid first-price auction where the bidders' utility function is given by $u(x)=x^{\alpha}$. We derive the symmetric equilibrium of the model using $b(\cdot)$ to denote the equilibrium bidding strategy. ${ }^{31}$

\footnotetext{
${ }^{31}$ Vickrey (1961) solves the first-price auction model for the case where the bidders are risk-neutral; Holt (1980), Riley and Samuelson (1981) assume identically risk-averse bidders. Cox et al.(1982) characterize the equilibria of the asymmetric model when the agents may have different $\alpha$ 's (CRRAM). For the completeness of the exposition, however, we outline the derivation of the symmetric equilibrium.
} 
Note that the expected utility of a bidder with realized value $v$ from bidding $s \equiv b(v)$ is

$$
\text { (10) } b^{-1}(s) \cdot[v-s]^{\alpha} \text {. }
$$

Differentiating with respect to $s$ gives:

$$
\frac{d}{d(s)} b^{-1}(s) \cdot[v-s]^{\alpha}-\alpha[v-s]^{\alpha-1} \cdot b^{-1}(s)=0
$$

This implies that

$$
\frac{d}{d(s)} b^{-1}(s) \cdot[v-s]=\alpha \cdot b^{-1}(s)
$$

Trying $s=B(\alpha) \cdot v$ gives $B(\alpha)=\frac{1}{1+\alpha}$.

Checking the second order conditions confirms that

$$
\text { (11) } b(v)=\frac{1}{1+\alpha} \cdot v
$$

is an equilibrium of the one-bid auction which completes the proof of Proposition 1.

To prove proposition 2 note that, by Bernoulli's inequality,

$$
\left[\frac{\alpha}{1+\alpha}\right]^{\alpha}=\left[1-\frac{1}{1+\alpha}\right]^{\alpha} \leq 1-\frac{\alpha}{1+\alpha}=\frac{1}{1+\alpha} \leq \frac{2-\alpha}{2}
$$

when $\alpha \leq 1$ and the inequalities are reversed when $\alpha \geq 1$.

From the solution for $l(v)$ above it follows that $l(v) \geq v / 3$ iff $\left[\frac{\alpha}{1+\alpha}\right]^{\alpha} \leq\left[\frac{2-\alpha}{2}\right]$ iff $\alpha \leq 1$ and the inequalities are reversed when $\alpha \geq 1$.

It immediately follows that $l(v)=v / 3$ [and $h(v)=2 v / 3$ ] when the bidder is risk-neutral (i.e., when $\alpha=1) ; l(v)>v / 3$ [and $h(v)>2 v / 3$ ] when the bidder is risk-averse (i.e., when $\alpha<1)$ and $l(v)<v / 3$ [and $h(v)<2 v / 3$ ] when the bidder is risk-seeking. This completes the proof of proposition 2 .

From Myerson's (1981) revenue equivalence principle it should immediately be clear that the two-bid auction is revenue-equivalent to the standard one-bid first-price auction when the bidders are risk-neutral. To prove Proposition 3 we have to compare the revenues for the cases where $\alpha \neq 1$. 
The expected revenue for the seller in the one-bid auction when the buyer with the highest valuation has a realized value of $v$ is

$$
\text { (12) } \frac{1}{1+\alpha} \cdot v
$$

From equation (9) it follows that the expected revenue for the seller in the two-bid auction when the buyer with the highest valuation has a realized value of $v$ is

$$
\text { (13) } \frac{L(v)}{H(v)} \cdot L(v) \cdot v+\frac{H(v)-L(v)}{H(v)} \cdot H(v) \cdot v \text {. }
$$

We now show that the seller prefers the two-bid mechanism over the one-bid mechanism when $\alpha>1$ and the inequality is reversed when $\alpha<1$ which proves Proposition 3 . From (12) and (13) above it is clear that it is enough to show that

$$
\text { (14) } \frac{L(v)}{H(v)} \cdot L(v) \cdot v+\frac{H(v)-L(v)}{H(v)} \cdot H(v) \cdot v>\frac{1}{1+\alpha} \cdot v
$$

for every $v \in[0,1]$ when $\alpha>1$ and the inequality is reversed when $\alpha<1$.

From the definitions of $H(\alpha)$ and $L(\alpha)$, however, we know that

$$
\begin{gathered}
\text { (15) } \frac{L}{H}=\frac{(1+\alpha) L}{1+\alpha L}, \quad \text { and } \\
\text { (16) } 1-\frac{L}{H}=\frac{1-L}{1+\alpha L} .
\end{gathered}
$$

Substituting (15)-(16) into (14) and rearranging we get the inequality

$$
L>\frac{1}{1+\alpha+\alpha^{2}}
$$

Substituting the definition of $\mathrm{L}$ we get the inequality

$$
\left(\frac{\alpha}{1+\alpha}\right)^{\alpha}<\frac{\alpha}{1+\alpha}
$$

which clearly holds when $\alpha>1$ and is reversed when $\alpha<1$. This completes the proof of Proposition 3.

Next, we examine the expected utility of a buyer with valuation $v$ in the two mechanisms. 
Plugging (11) into the objective (10) gives the expected utility for a bidder with valuation $v$ in the one-bid auction:

$$
\text { (17) }\left[\frac{\alpha}{1+\alpha}\right]^{\alpha} \cdot v^{1+\alpha}
$$

The corresponding equation for the two-bid auction mechanism is :

$$
\text { (18) } \frac{L(v)}{H(v)} \cdot v \cdot[v-l(v)]^{\alpha}+\frac{H(v)-L(v)}{H(v)} \cdot v \cdot[v-h(v)]^{\alpha} \text {. }
$$

Formally, we will now show that

$$
\text { (19) } \frac{L(v)}{H(v)} \cdot v \cdot[v-l(v)]^{\alpha}+\frac{H(v)-L(v)}{H(v)} \cdot v \cdot[v-h(v)]^{\alpha}>\left[\frac{\alpha}{1+\alpha}\right]^{\alpha} \cdot v^{1+\alpha}
$$

when $\alpha<1$ and the reverse inequality holds when $\alpha>1$, as proposed in Proposition 4 . (Note immediately that the two sides are indeed equal when $\alpha=1$ ).

From the definitions of $H(\alpha)$ and $L(\alpha)$ we have

$$
\begin{aligned}
& \text { (20) } 1-H=\frac{\alpha}{1+\alpha} \cdot[1-L], \\
& \text { (21) }\left[\frac{\alpha}{1+\alpha}\right]^{\alpha}=\frac{1-(1+\alpha) L}{1-L} .
\end{aligned}
$$

Substituting (15)-(16) and (20)-(21) into (19) and rearranging we get the inequality

$$
(22) \quad(1-L)^{\alpha+1}>1-L-\alpha \cdot(1+\alpha) \cdot L^{2}
$$

Plugging in the definition of $L$ and rearranging we get

$$
\text { (23) }(1+\alpha)^{\alpha}>\left[1+2 \alpha-\left[\frac{\alpha}{1+\alpha}\right]^{\alpha} \cdot(1+\alpha)\right] \cdot\left[1+\alpha-\left[\frac{\alpha}{1+\alpha}\right]^{\alpha}\right]^{\alpha-1}
$$

This implies that

$$
\left[\frac{1+\alpha-\left[\frac{\alpha}{1+\alpha}\right]^{\alpha}}{1+\alpha}\right]^{\alpha}<\frac{1+\alpha-\left[\frac{\alpha}{1+\alpha}\right]^{\alpha}}{1+2 \alpha-(1+\alpha)\left[\frac{\alpha}{1+\alpha}\right]^{\alpha}}
$$

Since however

$$
\frac{1+\alpha-\left[\frac{\alpha}{1+\alpha}\right]^{\alpha}}{1+\alpha}=1-\frac{1}{1+\alpha}\left[\frac{\alpha}{1+\alpha}\right]^{\alpha}
$$


and for $\alpha<1$

$$
1-\frac{1}{1+\alpha}\left[\frac{\alpha}{1+\alpha}\right]^{\alpha}<1-\left[\frac{\alpha}{1+\alpha}\right]^{\alpha+1}
$$

it immediately follows that

$$
\left[\frac{1+\alpha-\left[\frac{\alpha}{1+\alpha}\right]^{\alpha}}{1+\alpha}\right]^{\alpha}<1-\left[\frac{\alpha}{1+\alpha}\right]^{1+\alpha} .
$$

To prove (24) it is thus enough to show that for $\alpha<1$,

$$
\text { (26) } 1-\left[\frac{\alpha}{1+\alpha}\right]^{1+\alpha}<\frac{1+\alpha-\left[\frac{\alpha}{1+\alpha}\right]^{\alpha}}{1+2 \alpha-(1+\alpha)\left[\frac{\alpha}{1+\alpha}\right]^{\alpha}} \text {. }
$$

Direct algebra shows that this is equivalent to

$$
\frac{\alpha\left(1-\left[\frac{\alpha}{1+\alpha}\right]^{\alpha}\right)}{1+2 \alpha-(1+\alpha)\left[\frac{\alpha}{1+\alpha}\right]^{\alpha}}<\left[\frac{\alpha}{1+\alpha}\right]^{1+\alpha}
$$

which under some additional manipulations becomes:

$$
\text { (28) }\left[1-\left[\frac{\alpha}{1+\alpha}\right]^{\alpha}\right]^{2}<\left[\frac{\alpha}{1+\alpha}\right]^{1+\alpha}
$$

More algebra gives

$$
\text { (29) }(1+\alpha)^{\alpha}-\alpha^{\alpha}<\alpha^{\frac{\alpha+1}{2}}(1+\alpha)^{\frac{\alpha-1}{2}} \text {, }
$$

which in turn is equivalent to

$$
\text { (30) }\left[\frac{1+\alpha}{\alpha}\right]^{\frac{\alpha-1}{2}}>\left[\frac{1+\alpha}{\alpha}\right]^{\alpha}-1 \text {. }
$$

To prove (19) it is thus enough to show that inequality (30) holds when $\alpha<1$. This, however, follows directly from the fact that the LHS and the RHS of the inequality increase in $\alpha$; are equal when $\alpha=1$; and the derivative of the LHS (with respect to $\alpha$ ) is lower than the derivative of the RHS (with respect to $\alpha$ ), for every $\alpha$.

A symmetric argument shows that inequality (19) is reversed when $\alpha>1$ which completes the proof of Proposition 4.

Finally, we need to prove Proposition 5. 
This, however, follows directly from slight modifications on the arguments used in the proof of Proposition 1:

Using subscript $i$ to denote the bidding strategy of agent $i$ we get the following first order conditions for the asymmetric case (see equations (6) and (7) above):

$$
\begin{gathered}
-\alpha_{i}\left[v_{i}-l_{i}\left(v_{i}\right)\right]^{\alpha_{i}-1} \cdot h_{j}^{-1}\left(l_{i}\left(v_{i}\right)\right)+\left[v_{i}-l_{i}\left(v_{i}\right)\right]^{\alpha_{i}} \cdot \frac{1}{h_{j}^{\prime}\left(l_{i}\left(v_{i}\right)\right)}-\left[v_{i}-h_{i}\left(v_{i}\right)\right]^{\alpha_{i}} \cdot \frac{1}{h_{j}^{\prime}\left(l_{i}\left(v_{i}\right)\right)}=0 \\
(33) \quad-\alpha_{i} \cdot\left[h_{j}^{-1}\left(h_{i}\left(v_{i}\right)\right)-h_{j}^{-1}\left(l_{i}\left(v_{i}\right)\right)\right]+\left[v_{i}-h_{i}\left(v_{i}\right)\right] \cdot \frac{1}{h_{j}^{\prime}\left(h_{i}\left(v_{i}\right)\right)}=0
\end{gathered}
$$

Trying

$$
\text { (34) } l_{k}\left(v_{k}\right)=L_{k}\left(\alpha_{k}\right) \cdot v_{k} \quad \text { and } \quad h_{k}\left(v_{k}\right)=H_{k}\left(\alpha_{k}\right) \cdot v_{k}
$$

for $k=i, j$ in (32) and (33) and multiplying both equations by the constant $H_{j}$ gives the same first order conditions as obtained for the symmetric model. This (together with the argument used to prove Proposition 2 for the symmetric model) completes the proof of Proposition $5 .{ }^{32}$

\footnotetext{
${ }^{32}$ The bounds on $v_{i}$ stated in the proposition is imposed for the "usual" reasons; see, for instance, Cox et al.(1982).
} 


\section{Appendix B:}

Scatterplot of the bids (one-bid auction, phase 1)

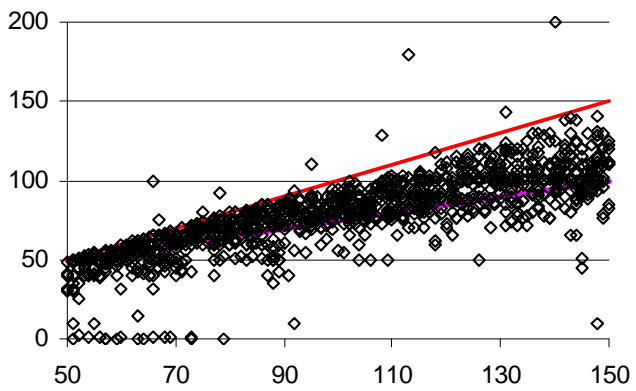

Scatterplot of the high-bids (two-bid auction, phase 1)

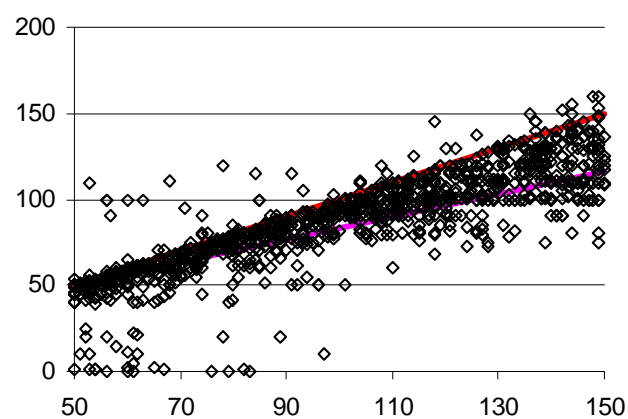

Scatterplot of the low-bids (two-bid auction, phase 1)

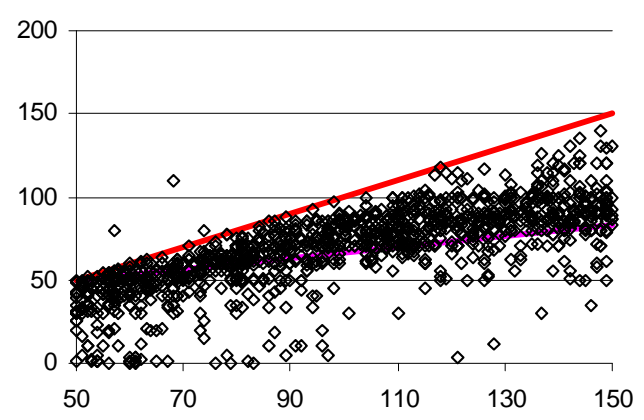

Scatterplot of the bids (one-bid auction, phase 2)

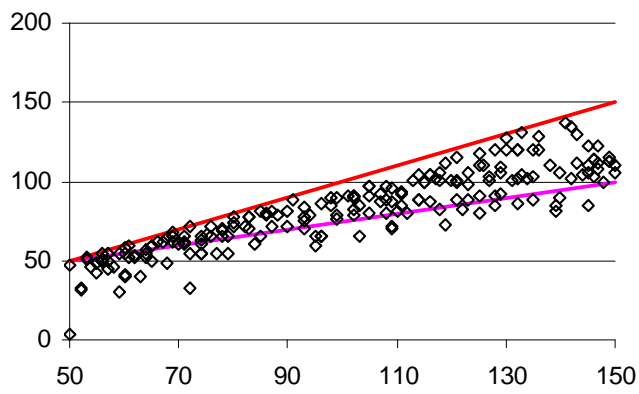

$\diamond$ real bidding RNE bidding truthful bidding
Scatterplot of the high-bids (two-bid auction, phase 2)

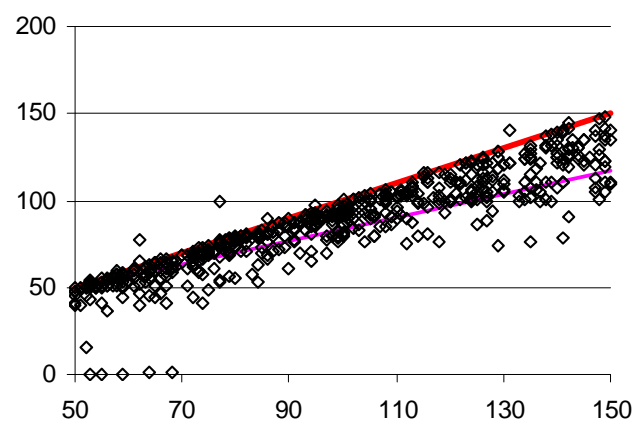

$\diamond$ real bid high RNE bid high truthful bidding
Scatterplot of the low-bids (two-bid auction, phase 2)

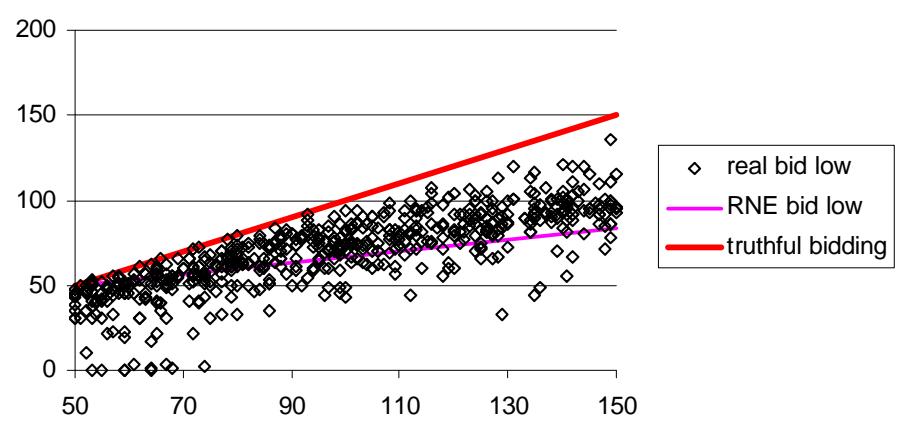

Figure B.1: Scatterplots of submitted bids

(the horizontal axes denote the private values, the vertical axes denote the bids) 


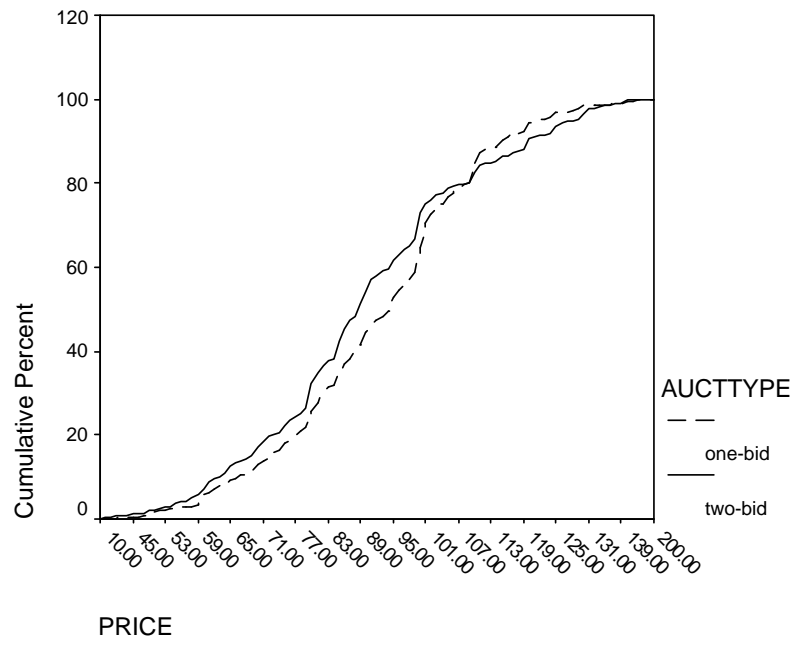

Figure B.2: Cumulative distribution function of the prices (for both auction types)

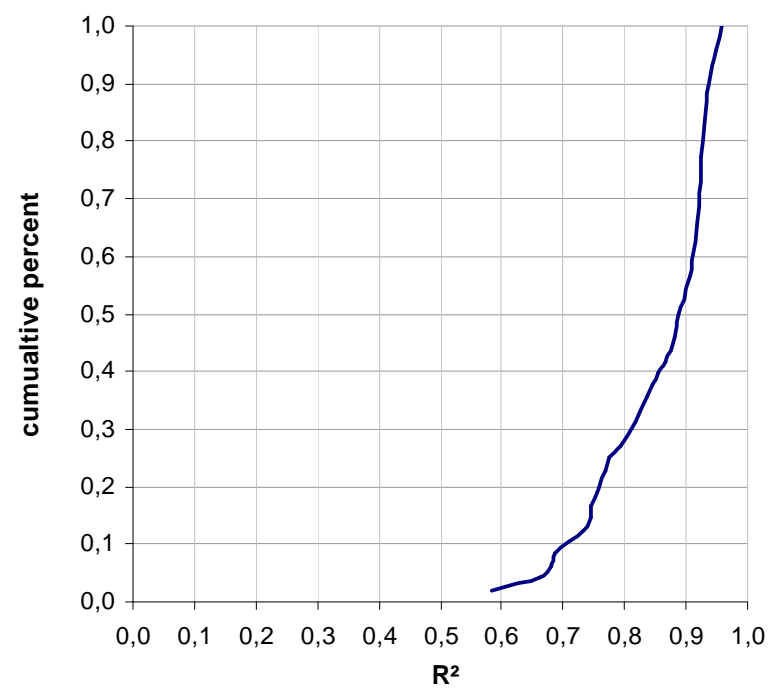

Figure B.3: Distribution of $\mathrm{R}^{2}$ statistic (SURE model) 


\section{Appendix C:}

\section{Translated instructions ${ }^{33}$}

Please, read these instructions carefully. They are identical for all participants.

During the experiment you will take part in several auctions. In every auction a fictitious commodity is for sale which you can resell to the experimenters. You are one of two bidders. In every auction the private reselling value $v$ of each bidder is independently drawn from the interval $50 \leq v \leq 150$, with every integer number between 50 and 150 being equally likely. Each bidder may place integer bids in the range from 0 to 200 . There are two different auction types.

\section{Type 1 (one-bid auction):}

You and your partner have to submit only one bid, i.e., to offer a (single) price at which you are willing to buy the commodity. The bidder with the highest bid (among the two of you) buys the commodity. He pays his own bid and receives his reselling value. The other bidder does not pay anything and does not receive anything. If the both bids are equal, the buyer is chosen randomly (by the flip of a fair coin).

\section{Type 2 (two-bid auction):}

You and your partner have to submit two bids, a high-bid and a low-bid, i.e., to offer two prices at which you are willing to buy the commodity. The bidder with the highest bid (among the four bids) buys the commodity and receives his reselling value. The price he has to pay is determined as follows:

- he pays his own low-bid, if his low-bid is higher that the high-bid of the other bidder;

- he pays his own high-bid, otherwise.

The other bidder does not pay anything and does not receive anything. If the both high-bids are equal, the buyer is chosen randomly (by the flip of a fair coin).

\footnotetext{
${ }^{33}$ This is a shortened and translated version of the instructions. For the original instructions (in German), please contact Radosveta Ivanova-Stenzel.
} 
After you have placed your bid(s) you are informed whether or not you are the buyer, about the price, which has to be paid by the buyer, your private reselling value, your own $\operatorname{bid}(\mathrm{s})$, the bid(s) of the other bidder, how much you have earned in this auction, your total profit up to this time and your average profit in each auction type (per auction type). Altogether, you will play 48 successive auctions, which consist of 4 cycles of 12 bidding rounds. In one cycle each participant plays first 6 times the auction type 1 and then 6 times the auction type 2. At the beginning of each round you are informed about the actual auction type and your actual private reselling value of the item. In each auction the bidder groups are formed randomly.

Any decision you make is anonymous and cannot be related to you personally by your co-bidders. If you have questions, please, raise your hand. We will then clarify your problems privately.

\section{Additional Instructions (phase 2):}

You now will play another 16 auctions. You can choose the auction type according to the following rules: 7 of the 8 participants will be asked to choose one of the two auction types (one-bid vs. two-bid) before they observe their realized reselling values. The 8-th participant will be automatically assigned to one of these auction types in order to make the number of players in each auction type even. For instance, if 4 players have chosen the one-bid auction and 3 players have chosen the two-bid auction than the last player will be asked to participate in a two-bid auction so that there will be two pairs playing each type of auction. The identity of the "8-th" player (the one that is not asked to choose the auction type) will be changed in each round, so that each participant will play the balancing role of player 8 twice during the 16 rounds. After the auction type is determined, the auction is played as in the first phase. 